\title{
Belphégor
}

\section{Emilio Salgari, Le Aquile della steppa}

\section{Paola Irene Galli Mastrodonato}

\section{(2) OpenEdition}

\section{Journals}

\section{Edizione digitale}

URL: http://journals.openedition.org/belphegor/506

DOI: 10.4000/belphegor.506

ISSN: 1499-7185

\section{Editore}

LPCM

\section{Notizia bibliografica digitale}

Paola Irene Galli Mastrodonato, «Emilio Salgari, Le Aquile della steppa », Belphégor [En ligne], 12-1 |

2014, mis en ligne le 12 juin 2014, consulté le 22 septembre 2020. URL : http://

journals.openedition.org/belphegor/506 ; DOI : https://doi.org/10.4000/belphegor.506

Questo documento è stato generato automaticamente il 22 settembre 2020.

\section{(c) (1) (9)}

Belphégor est mis à disposition selon les termes de la Licence Creative Commons Attribution - Pas d'Utilisation Commerciale - Pas de Modification 4.0 International. 


\section{Emilio Salgari, Le Aquile della steppa}

Paola Irene Galli Mastrodonato

NOTIZIA

Emilio Salgari, Le Aquile della steppa, a cura di Luciano Curreri, Milano: Greco \& Greco Editori, 2010, 390 pp. 
Con grande intuito e con la consueta perspicacia critica, Luciano Curreri ha curato questa pregevole edizione del romanzo di Emilio Salgari, Le Aquile della steppa, nella sua prima versione a stampa per i tipi di Donath editore a Genova, tra il 1905 e il 1906. Titolo appartenente all'ultima produzione dello scrittore veronese, quella che si situa “un po' prima della fine", parafrasando un volume collettivo di recente pubblicazione, questo romanzo rivela una complessità e un "valore" di ricezione del tutto particolari. Di ambientazione sempre Orientale, ma di quel versante che fa dell'“Orso russo" il potere di riferimento dominante, il romanzo ha al centro la figura affascinante e seducente del giovane Hossein, figlio prediletto di un grande

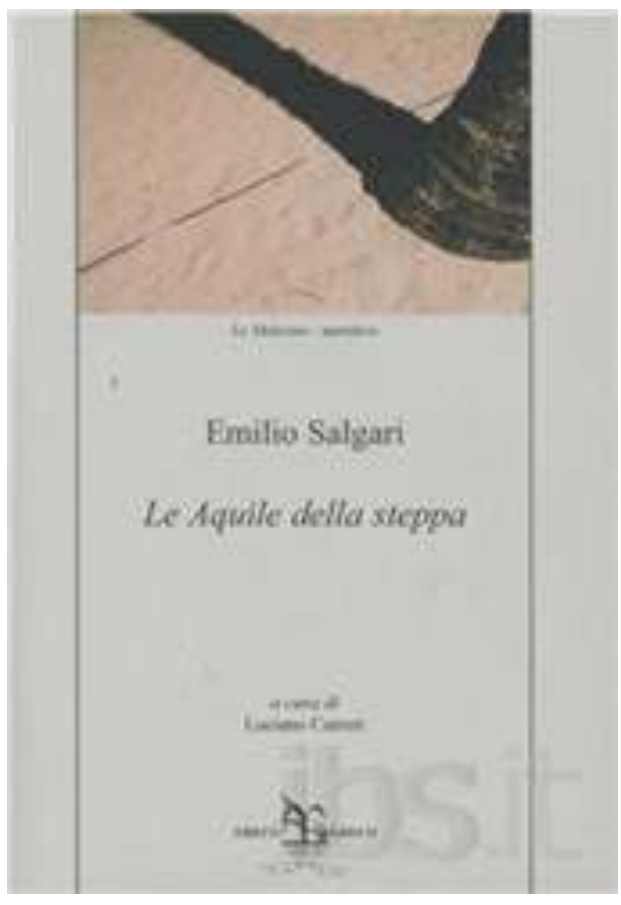
capo, il beg Giah Agha, appartenente al clan dei Sarti, una delle tante tribù che si trova spersa nel grande oceano delle "steppe turchestane" (p. 10) dove imperversano diversi gruppi etnici di etnia turca e asiatica, tra le quali appunto anche quella dei predoni pronti a tutto, le Aquile.

2 Fin dall'incipit, ci troviamo immersi in una sequenza mozzafiato ad alta adrenalina, dove Salgari dispiega tutto il suo talento, ormai maturo, di grande narratore saldamente ancorato alla tradizione del "romance" (Curreri, p. 371) piuttosto che a quella autoriflessiva del novel, preferita dal "canone" occidentale (Ibid., p. 369). Infatti, il clan del beg ha intercettato e catturato una spia delle Aquile, responsabili del ratto di Talmà, fidanzata di Hossein, per conto del vile e invidioso Abei, cugino di quest'ultimo. Senza sapere nulla del retroscena, il lettore prende visione in modo oserei dire brutale e senza mediazioni del castigo o piuttosto della tortura che attende lo sfortunato prigioniero, un mestvire o cantastorie di professione, con il "supplizio spaventevole" della tomba di gesso che lentamente stritolerà il malcapitato. Ebbene, l'uso perfetto della tecnica modernista dell'inizio in medias res non fa che enfatizzare il valore di aggancio immediato alla realtà della narrazione e all'universo del racconto, come sempre poliedrico e ricco di riferimenti storici e ambientali precisi e accurati. Dalla descrizione del mare fluttuante di erbe altissime delle grandi praterie che si estendono dall'Aral al Mar Caspio e della contrapposta "steppa della fame" che subisce l'influsso venefico dei vasti deserti cinesi, fino al reportage, potremmo dire, in stile giornalistico della cerimonia dei flagellanti sciiti alla quale assistono Hossein e Tabriz, il "gigantesco turcomanno" che veglia su di lui, e che mi conferma nella straordinaria erudizione del nostro più grande scrittore di avventure. Ci troviamo a Kitab, città del khanato di Bukara, sotto assedio da parte delle truppe dello zar, ed ecco come ci viene presentata la "festa del sangue" in onore di Hussein e Alì:

3 Un certo numero di fanatici, scelti fra i molti concorrenti, si mettono a capo delle processioni, armati di sciabole, di jatagan, di pugnali, di coltellacci e cinti di pesanti catene che trascinano fragorosamente per le vie e si tagliuzzano con una voluttà feroce 
e ributtante il viso, le braccia, il petto, invocando a squarciagola i loro santi protettori. (p. 179)

4 Mi ricordo con grande nitidezza lo spettacolo impressionante di uomini in processione (piuttosto che "fanatici") che si trascinavano sanguinanti e urlanti sotto i colpi di grosse catene e bastoni per le strade di Teheran, mentre io, ragazzina di nove anni, sbirciavo la scena senza farmi vedere, dalle finestre della scuola di suore italiane dove frequentavo la quarta elementare. Portentoso effetto di ricezione, che non fa che confermarci, credo, nell'ormai avvenuta rivalutazione di un esponente di spicco delle nostre Lettere, in quest'anno che si è appena concluso, il 2011, che ne commemora il centenario della tragica scomparsa. 